\title{
UDL - From Disabilities Office to Mainstream Class: How the Tools of a Minority Address the Aspirations of the Student Body at Large
}

\author{
Frederic Fovet \& Heather Mole
}

McGill University

Confronted by the increasingly changing and varied nature of disabilities in higher education (Bowe, 2000; McGuire \& Scott, 2002), disability service providers across North America are progressively moving away from targeted remedial assistance focusing on the disabilities of students to a less frontline role involving the sensitization of faculty around strategies that seek to widen access and develop awareness (Sopko, 2008). Universal Design is hence often the model of choice (Rose, Harbour, Johnston, Daley, \& Abarbanell, 2006). It incorporates extensive use of technology and seeks the implementation of winning conditions in the classroom space that reduce or eliminate the need for later remedial work with students (Burgstahler, 2006). The hypothesis of this paper is that Universal Design, though conceived as a tool for a specific clientele, may quickly transpire to be the model best suited to serve the needs of the student body at large by meeting the wider educational aspirations of the 21st century. Not only do its strategies and goals allow wider access to students with disabilities, but they allow the integration of the 'millennium learners,' encourage higher student retention, guarantee higher rates of graduation and establish greater equity and respect for diversity.

\section{Introduction}

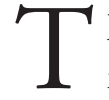

his paper offers a methodological snapshot of an institution's process of Universal Design for Learning (UDL) implementation. It considers the outcomes observed beyond the parameters of disability services and analyzes qualitative observations made by disabilities service providers but also faculty, administrators and students. The implementation of UDL represented a radical move away from a medical model of disability in the management of disabilities issues in higher education, but it soon became apparent, through the implementation process described, that the scale of outcomes went far beyond issues of disabilities. It is hypothesized in this analysis that UDL and teaching and assessment practices associated with it have an impact on learners at large. 


\section{Context}

The Disability Service unit of the institution considered has been in existence for approximately two decades and its mandate has been forged through a historical desire to facilitate access to students with traditional disabilities: sensory, physical, and mobility disabilities. In this respect, it has been relatively successful in creating awareness and in creating access, for students with very specific needs, where none previously existed or had yet been conceived. The unit has more recently committed to the implementation of the social model of disability (Barnes, Mercer, \& Shakespeare, 1999) and Universal Design for Learning (Gordon, Gravel, \& Schifter, 2009), but it has never firmly secured the resources or found the determination to examine the concrete impact of this commitment. Since September 2011, however, the unit has launched a structured and momentous push for tangible UDL implementation and the first phase of this task has focused on impressing the importance of this paradigm shift, not just on faculty but also on crucial campus partners: Teaching and Learning Services (TLS), the Social Equity and Diversity Education (SEDE) Office, the Sustainability Office and, of course, senior administration. Students have also been involved through consultation, quality assessment exercises and formal training on the impact and application of this theoretical framework. The study reviews outcomes reported after 12 months of implementation process.

\section{What is Universal Design?}

Universal Design is a framework, which is increasingly appealing as it allows for legal imperatives surrounding access to be addressed seamlessly and in a manner that is sustainable and inclusive (Howard, 2004). Design and conception are the focus, rather than the individual or any specific impairment (Rose \& Gravel, 2010). Universal design is originally and historically an architectural framework, which includes seven principles (NC State University, 1997): equitable use, flexible use, simple and intuitive use, perceptible information, tolerance for error, low physical effort, and size and space for approach and use. It has since then been adapted for the learning environment. If, indeed, buildings can be designed in such a way that access is widened to the greatest possible number of users, so can the classroom experience (Gradel \& Edson, 2010).

Universal Design for Learning more specifically is a teaching approach, which considers how curriculum, instruction, and assessment can meet the learning needs of the greatest number while maintaining academic rigour (Rose \& Gravel, 2010). Universal Design for Learning promotes three core principles; multiple means of representation; multiple means of expression and action; and multiple means of engagement at each level of the course, be it instruction, resource or evaluation (Rose et al., 2006). The social model of disability argues that it is the environment that can disable the student when badly designed, rather than any characteristics that are inherent to the individual (Barnes, Mercer, \& Shakespeare, 1999; Howard, 2004). Therefore, by implementing UDL, the classroom has the potential to offer flexibility and options so that students are enabled in their learning experience and barriers are removed. The experience of students with attention deficit/hyperactivity disorder (ADHD), who may find higher education alternatively oppressive or congenial, depending on the instructional style in the classroom, is an eloquent illustration of the potent lessons the social model has to offer us with regards to post-secondary teaching practices (Allsopp, Miskoff, \& Bolt, 2005).

\section{Methodology}

This paper presents the analysis of qualitative data collected in the one-year initial implementation phase of a UD promotion and implementation project seeking to alter the model used by a higher education disability service provider. Qualitative data was collected from faculty, administrators, and employees at large through the delivery of UD implementation workshops of various formats (Collins, 1998). By their very nature, these interactive workshops presented a perfect forum to collect qualitative data in a semi-directive frame (Barbour et al. 2000). Data was collected both orally through verbal interaction, but also through Quality Assurance surveys used systematically after each of these workshops (Bogdewic, 1999). The implementation of UD on this campus is still a 'work-in-progress,' and the process has not been completed. There seemed, however, to be enough tangible findings registered already to draw some conclusions on the impact of this initiative for faculty and learners at large on the campus. 


\section{Findings}

\section{Dialogue with faculty}

Faculty members were invited to attend workshops on UDL and they were given the opportunity to request workshops. No faculty members are currently obliged to attend the workshops. The invitation goes to any faculty member who has a student registered with the institution's disability service provider in their class where that student has requested that an email confirming their registration be sent. Some faculty members attend a more general workshop for any staff, faculty, or graduate students that pertains to disability, access and universal design. The feedback collected from faculty members and course instructors indicates that the content of the UDL implementation drive echoes instructors' concerns and preoccupations about learning outcomes generally. In fact many commented that UDL incorporates many pedagogical notions already familiar to the instructors such as Gardner's multiple intelligences (Almeida et al., 2010), differentiated teaching (Subban, 2006), and inclusive provisions (Voltz, Brazil, \& Ford, 2001). Instructors often appreciated and mirrored back to the facilitators of the workshops the idea that UDL promotion effectively marked the end of the culture of the disabilities 'specialist;' in this sense it was seen as re-empowering for course instructors as it offered them tools to manage disabilities issues on their own turf. One of the other registered outcomes was that the instructors reported having gained awareness, through the UD content, of the existence and needs of 'diverse learners.' This seemed to blend issues such as legal preoccupations and imperatives with respect to disabilities, the disabilities minority discourse as well as more general campus agendas. Many participants evoked a similarity of purpose between objectives they had heard expressed by teaching support (Teaching and Learning Services in this particular institution) and the new objectives that were presented to them within the UDL framework. Faculty were concerned about the workload that this might entail; however, the workshops encouraged gradual, sustainable changes rather than complete overhauls of course design. Suggestions for big impact changes were made such as providing notes, background information or lecture slides to the whole class.

\section{Dialogue with other campus stakeholders}

Campus stakeholders included student services groups (e.g., counseling services, mental health services, international student services, first year office, scholarships and students aid and career service) as well as student affairs (e.g., enrolment and registration, withdrawals etc), student advising, SEDE, teaching and learning services, libraries, graduate studies and residences. This group also included students registered with the disability service provider who were part of the advisory group for the office. One of the recorded outcomes from campus at large was that the three principles of UDL in fact applied to any interface with students in service provision, regardless of their being affected by a disability. These participants reported the satisfaction of being offered a 'common language' to share understanding about access and diversity generally. Expressed links were made by participants between the core notions being presented to them as part of UDL promotion and wider issues of equity and diversity being raised by the diversity partners (SEDE office in this particular institution). These remarks echo the findings of literature that emphasizes the impact of UDL in matters of equity and diversity in service provision generally (Uzes \& Connelly, 2003). It was stressed by participants that the use of this common language would also have the advantage of offering a continuum of services from a user perspective and allow more seamless transition from institution to institution if applied universally. Similarly, it was felt that the implementation of this framework would help close the gap between academic and nonacademic services as UD is applicable to the campus at large, not just in the class environment. In this sense, UD implementation is seen as complementary to other change processes such as sustainability audits or diversity drives. There is the perception that there is a clear synchronicity between various concepts and objectives in the mainstream campus agenda. Students were excited by the potential of UD to change their experience on campus, whether in the classroom or in their interactions with service providers. They were keen to be involved in promotional events for UD where possible so that their voice could be heard, and they have collaborated in and producing a promotional video for UD.

\section{Dialogue with senior administration}

Evaluated outcomes became relevant not just from an 
educational perspective but also from an administrative and management angle. These parallel outcomes were recorded through dialogue with senior administration. Three distinct threads of discussion and comment appeared throughout the data analysis: resource management, sustainability, and inclusion.

\section{Resource management}

Participants were very sensitive to the issue of efficient resource management as one of the justifications for UDL implementation. Of course, this related mostly to best practices in the management of disability issues. However, the discussion soon encompassed much wider questions such as the varied needs of diverse learners, their retention, and ways of securing higher graduating rates - with cost being the lens driving scrutiny. Little distinction was made, with respect to these threads of discussion, between students with disabilities and non-traditional students at large. The exploration of the three principles of UDL quickly reveals that the solutions sought and the outcomes targeted benefit not just students with disabilities but students at large. Literature supports the assumption that such pedagogical best practices support learners of widely differing profiles, such as mature students, students with families, and second language learners (i.e., the increasingly large number of students in Higher Education who do not fall within a conventional and generic - some will say obsolete - stereotype [Sopko, 2008]).

\section{Sustainability}

It was well identified and analyzed by participants that the traditional 'accommodations' approach to disability is an ad hoc process of retrofitting, repeated each semester, for each course, for each individual student making a request, and as such is a highly costly and consumable process. The procedure in itself is a non-renewable use of resources. In this specific institution, this process of service provision has been identified as not conforming to the sustainability objectives of the campus (Vision, 2020), and examined in its audit of renewable development. There has been a tangible synchronicity, therefore, between UD promotion and the push for sustainability benchmarking in culture, practices and service provision, according to the participants' feedback. Universal Design, by focusing on modification to the environment, constitutes a sustainable approach to the management of the diverse needs of learners (Harrison, 2006). Participants in this category once again explicitly stressed that various campus initiatives could gain from each other's successes offering the benefit of economies of scales.

\section{Inclusion}

This convergence of discourse was also expressly mentioned by the participants with regards to inclusion. Participants expressed concern over the lack of awareness of inclusion principles existing in higher education. It was felt generally that post-secondary institutions were ill prepared to meet the expectation of students with regards to inclusive practices. The imperative, which is central to UD, to provide services in class and within a mainstream environment - as well as the resistance observed from course instructors - were not seen by participants as specific to the issue of disability. They represented, according to the feedback collected, challenges that were fundamental to the integration of millennium learners in post-secondary education.

\section{Outcomes}

Participants reported a contextual relevance of the UDL material in a wider shift in paradigm; they described this shift in objectives and mission as a move from a researchcentered culture to one that is also student-centered. The potential of Universal Design implementation certainly comes at a propitious time when the drive for diversity in education is increasingly present on the agenda in higher education (Tegmark-Chita, Gravel, Serpa, Domings, \& Rose, 2012). In this specific university, for example, Universal Design was unambiguously highlighted as an area of particular focus in the Principal's Taskforce Report on Diversity, Excellence and Community Engagement (2011). The wider objective of increasing diversity on campus is exceptionally well served by the model, and it has the advantage of turning the disability service framework, traditionally a minority and often ignored agenda, into a mainstream concern and a discourse serving the needs of students at large. Most campus administrations in North America are only too aware of the shift in paradigm, which is transforming the higher education landscape. Even the most renowned research universities can no longer hope to attract and retain sufficient numbers of students without addressing their needs and expectations proactively (Pomerantz, 2006). This is an auspicious time to integrate UD into a wider diversity drive, which is 
crucial to guarantee applications, retention and graduation rates in line with campus objectives and governmental expectations. The neoliberal agenda, which has long promoted research activities which themselves attracted wider funding as the prior focus of higher education institutions, has now come full circle and is tangibly and demonstratively placing diverse student needs on the table as the key element to long term survival and sustainable growth (Tinto, 2005; Swail, Redd, \& Perna, 2003). It appears crucial for disability service providers to take advantage of this auspicious development (Strange \& Banning, 2001) and for campuses to, reciprocally, use disability service provision statutory imperatives as a wedge to trigger quick implementation of larger objectives relating to inclusion and diversity of learners at large.

\section{References}

Allsopp, D., Miskoff, E., \& Bolt, L. (2005). Individualized course-specific strategy instruction for college students with learning disabilities and ADHD: Lessons learned from a model demonstration project. Learning Disabilities Research \& Practice, Vol. 20(2), pp. 103-118

Almeida, L.S., Prieto, M.D., Ferreira, A.I., Bermejo, M.R., Ferrando, M., \& Ferrandiz, C. (2010). Intelligence assessment: Gardner multiple intelligence theory as an alternative. Learning and Individual Differences, Vol. 20(3), pp. 225-230.

Barbour, R., Featherstone, V., \& Members of WoReN. (2000). Acquiring qualitative skills for primary care research. Review and reflections on a threestage workshop. Part 1: Using interviews to generate data. Family Practice, Vol. 17, pp. 76-82.

Barnes, C., Mercer, G., \& Shakespeare, T. (1999). Exploring disability: A Sociological introduction. Malden, MA: Blackwell.

Bogdewic, S. (1999). Participant observation. In B. Crabtree \& W. Miller, (Eds.) Doing qualitative research (pp. 47-69). 2nd ed. Thousand Oaks, CA: Sage.

Bowe, F.G. (2000). Universal design in education: Teaching non-traditional students. Westport, CT: Bergin \& Garvey.

Burgstahler, S. E. (2008). Universal design in higher education. In S.E. Burgstahler \& R.C. Cory (Eds.), Universal design in higher education: From principles to practice (pp. 3-20). Cambridge, MA: Harvard Education Press.

Collins P. (1998). Negotiating selves: reflections on 'unstructured' interviewing. (WWW) Sociology Research Online, 3(3).

Gordon, D.T., Gravel, J.W., \& Schifter, L.A. (2009). A policy reader in universal design for learning (pp. 209-218). Cambridge, MA: Harvard Education Press.

Gradel, K. \& Edson, A. J. (2010). Putting universal design for learning on the higher ed agenda. Journal of Educational Technology Systems, 38(2), 111-121.

Harrison, E. (2006). Working with faculty toward universally designed instruction: The process of dynamic course design, Journal of Postsecondary Education and Disability, Special Issue: Universal Design in Higher Education, 19(2), 152-162

Howard, K.L. (2004). Universal design for learning: Meeting the needs of all students. Learning and Leading with Technology, 31, 26-29.

McGuire, J., \& Scott, S. (2002). Universal design for instruction: a promising new paradigm for higher education. Perspectives, 28(2), 27-29.

NC State University, (1997). The principles of Universal Design Version 2.0 - 4/1/97 The Center for Universal Design Retrieved June 102013 from http://www.ncsu.edu/ncsu/design/cud/about_ud/ udprinciples.htm

Office of the Principal and Vice-Chancellor (2011). Principal's taskforce report on diversity, excellence and community engagement. Montreal: McGill.

Pomerantz, N.K. (2006). Student engagement: A new paradigm for student affairs. College Student 
Affairs Journal, 25(2), 176-185.

Rose, D.H. \& Gravel, J.W. (2010). Universal design for learning. In E. Baker, P. Peterson, \& B. McGaw (Eds.). International Encyclopedia of Education, 3rd Ed. Oxford: Elsevier.

Rose, D.H., Harbour, W.S., Johnston, C.S., Daley, S.G., \& Abarbanell, L. (2006). Universal design for learning in postsecondary education: Reflections on principles and their application. Journal of Postsecondary Education and Disability, 19(2), 17.

Sopko, K. M. (2008). Universal design for learning: Implementation in six local education Agencies. Alexandria, VA: Project Forum at the National Association of State Directors of Special Education.

Strange, C.C. \& Banning, J.H. (2001). Educating by design: Creating campus learning environments that work. San Francisco: Jossey-Bass.

Subban, P. (2006) Differentiated instruction: A research basis. International Education Journal, 7(7), 935947.

Swail, W.S., Redd, K.E., \& Perna, L.W. (2003). Retaining minority students in higher education: A framework for success. ASHE-ERIC Higher Education Report, 30(2). San Francisco: Jossey-Bass.

Tegmark-Chita, M., Gravel, J.W., Serpa, M. deL. B., Domings, Y., \& Rose, D.H. (2012). Using the Universal Design for Learning framework to support culturally diverse learners, Journal of Education, 192(1), 17-22

Tinto, V. (2005). Moving from Theory to Action. In A. Seidman (Ed.), College student retention: Formula for student success (pp. 317-333). Washington DC: ACE \& Praeger.

Uzes, K.B., \& Connelly, D. O. (2003). Universal Design in counseling center service areas. In J. L. Higbee (Ed.), Curriculum transformation and disability: Implementing Universal Design in
Higher Education (pp. 241-247). Minneapolis: University of Minnesota, General College, Center for Research on Developmental Education and Urban Literacy.

Vision 2020. (2012). Vision 2020: Creating a Sustainable McGill - Situational Analysis. Montreal: McGill.

Voltz, D.L., Brazil, N., \& Ford, A. (2001). What matters most in inclusive education: Apractical guide for moving forward. Intervention in School \& Clinic, 37, 23-31.

\section{Biographies}

Frederic Fovet is the Director of the Office for Students with Disabilities at McGill University. His research and practice focus on Social Emotional Behaviour Difficulties, inclusive education and Disabilities service provision.

Heather Mole is an Access Service Advisor in the Office for Students with Disabilities at McGill University. Her research focuses on the implementation of universal design in higher education and the social model of disability. 